1

10

\section{Molecular and rheological characterization of different cell wall fractions of} Porphyridium cruentum

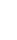

Tom M.M. Bernaerts ${ }^{a}$, Clare Kyomugasho $^{a}$, Noor Van Looveren ${ }^{a}$, Lore Gheysen $^{b}$, Imogen Foubert ${ }^{b}$, Marc E. Hendrickx ${ }^{a}$, Ann M. Van Loey ${ }^{a}$

Laboratory of Food Technology, Leuven Food Science and Nutrition Research Centre (LFoRCe), Department of Microbial and Molecular Systems $\left(\mathrm{M}^{2} \mathrm{~S}\right)$, Katholieke Universiteit Leuven, Kasteelpark Arenberg 22, Box 2457, 3001 Heverlee, Belgium

Authors are affiliated to:

a Laboratory of Food Technology (member of Leuven Food Science and Nutrition Research Center, LFoRCe), Department of Microbial and Molecular Systems $\left(\mathrm{M}^{2} \mathrm{~S}\right)$, KU Leuven, Kasteelpark Arenberg 22 box 2457, 3001 Heverlee, Belgium

b Laboratory Food and Lipids (member of Leuven Food Science and Nutrition Research Center, LFoRCe), Department of Microbial and Molecular Systems (M²S), KU Leuven Kulak, E. Sabbelaan 53, 8500 Kortrijk, Belgium

* Corresponding author

$$
\text { Fax: }+3216321960
$$

Telephone: +32 16321567

E-mail: ann.vanloey@kuleuven.be 


\section{ACCEPTED MANUSCRIPT}

\section{Abstract}

28 Cell wall related polysaccharides of the red microalga Porphyridium sp. were shown to be a promising source

29 of new sustainable thickening agents. Isolated extracellular polysaccharides (EPS) consisted of high molecular weight polymers, showing a higher intrinsic viscosity compared to several commercially used hydrocolloids. Aqueous solutions of EPS ( $2 \% \mathrm{w} / \mathrm{w})$ were characterized by substantial viscosities and weak gel behavior. Even though the extracted water soluble cell wall polysaccharides exhibited the same monosaccharide profile as EPS (composed of galactose, glucose, xylose and glucuronic acid), a lower molecular weight and intrinsic viscosity was observed for this fraction, resulting in poor rheological properties. Therefore, it was hypothesized that the physicochemical properties were related with a different molecular structural organization of these monosaccharides and sulfate groups. The main challenge for commercialization of extracellular polysaccharides of Porphyridium sp. remains the purification of these fractions to obtain polysaccharide extracts with low protein and salt contents.

\section{$39 \quad$ Keywords}

40 Red microalga, exopolysaccharides, molecular weight, intrinsic viscosity, thickening agent, gel behavior

\section{$41 \quad$ Highlights}

42 Extracellular polysaccharides (EPS) consist of high molecular weight polymers

43 EPS show a higher intrinsic viscosity than several currently used thickening agents

44 Cell wall polysaccharides have same sugar profile as EPS, but lower molecular weight

45 None of the polysaccharide solutions gel by cold-set or heat-set gelation

EPS show large potential as a new sustainable thickening agent

\section{Abbreviations}

$48 \quad \omega 3$-LC-PUFA omega-3 long chain polyunsaturated fatty acids

49 CWPS cell wall polysaccharides

50 EPMS extracellular polymeric substances

51 EPS extracellular polysaccharides 
52 wiCWPS water insoluble cell wall polysaccharides

53 wsCWPS water soluble cell wall polysaccharides

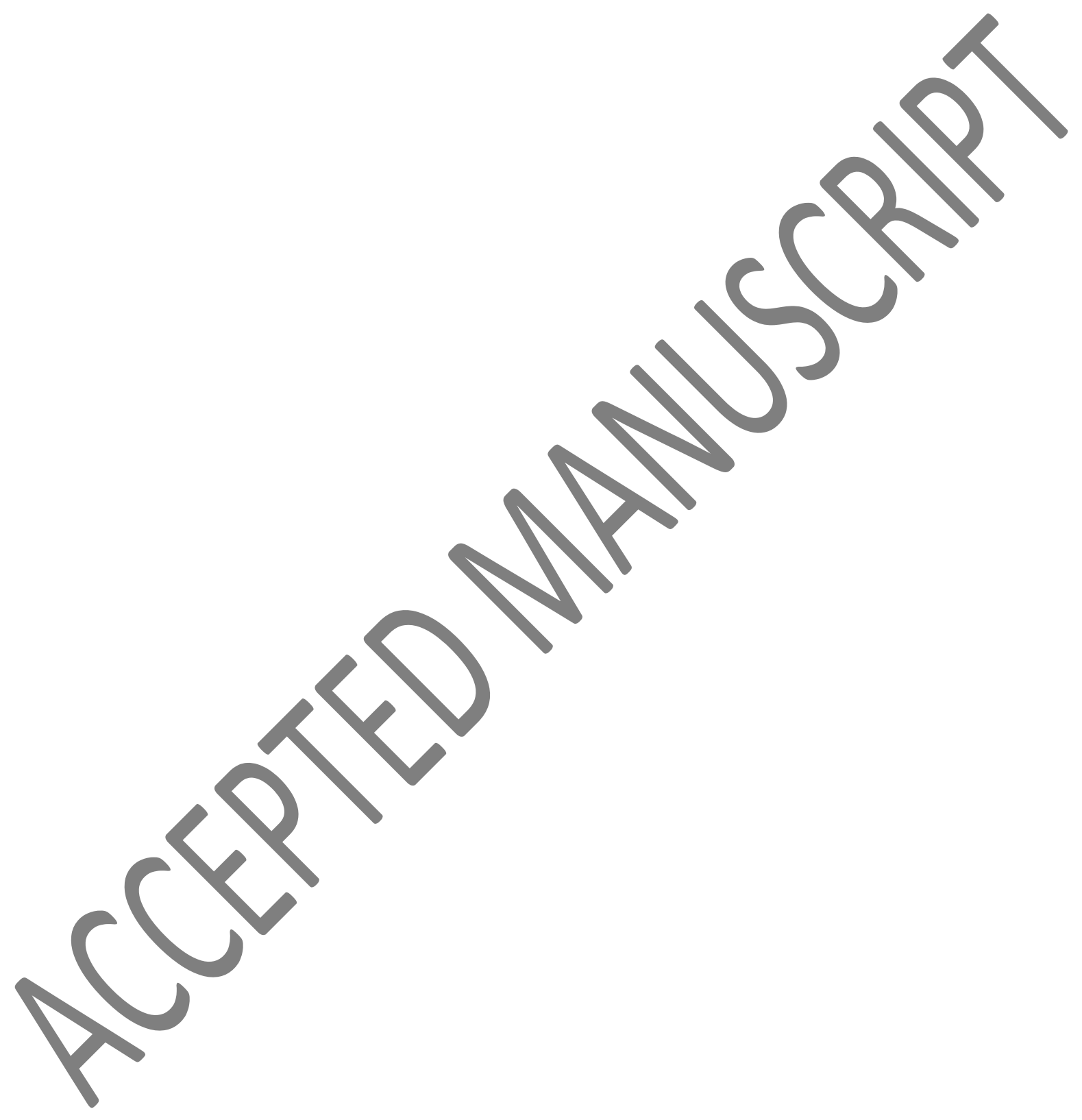




\section{Introduction}

A wide range of naturally available polysaccharides display several biotechnological functions towards industrial applications, including their use as structuring agents in the food industry (Imeson, 1997; Whistler, 2012). These polysaccharides are mainly extracted from land plants, such as starch, pectins and galactomannans, or from seaweeds, including alginates, agars and carrageenans. Whereas macroalgal polysaccharides have been successfully commercialized as thickening or gelling agents in food products, polysaccharides of microalgae have received little attention in this context, despite the several advantages associated with microalgae. For instance, autotrophic microalgae are considered a sustainable biomass source, due to their high photosynthetic efficiency and no competition with conventional crops for arable lands (Buono, Langellotti, Martello, Rinna, \& Fogliano, 2014). Moreover, several microalgae species are nowadays cultivated for commercialization of high-value products, including omega-3 long chain polyunsaturated fatty acids ( $\omega 3$-LC-PUFA), antioxidants and pigments, resulting in a waste stream of residual biomass (Matos, Cardoso, Bandarra, \& Afonso, 2017). Valorization of these waste streams, e.g. by extracting polysaccharides with biotechnological functions, could increase the economic relevance of microalgae. In this context, establishing the molecular structure of these polysaccharides might promote exploration of their functionality, which to date is only scarcely described.

Porphyridium sp. is a unicellular red microalga (Rhodophyta) whose cells are encapsulated in a sulfated polysaccharide complex. During growth, the external part of this capsule dissolves into the medium, imparting a viscosity increase of the medium. In literature, these polymers are often called EPS, referring to either extracellular polymeric substances, extracellular polysaccharides or exopolysaccharides. However, to clearly differentiate between the type of polymers included in this fraction, different terminology is used in this study, as previously described by Bernaerts et al. (2018). The term extracellular polymeric substances (EPMS) defines all polymeric material that is excreted into the aqueous environment, whereas the term extracellular polysaccharides (EPS) is used when only polysaccharides are considered. In contrast to the extracellular material, a large fraction of the cell wall complex (about 50 to $70 \%$ ) remains attached to the cell and is usually referred to as bound polysaccharides (Arad \& Levy-Ontman, 2010). So 
far, several authors have performed a molecular characterization of the extracellular polymers produced by Porphyridium sp., including monosaccharide composition, linkage analysis and quantification of sulfate esters and protein moieties (Geresh et al., 2009; Geresh, Adin, Yarmolinsky, \& Karpasas, 2002; Geresh \& Arad, 1991; Gloaguen et al., 2004). EPS of Porphyridium sp. are suggested to be composed of D-xylose, D- and L-galactose and D-glucose, although various molar ratios of these monosaccharides were reported (Geresh et al., 2002; Patel et al., 2013; Roussel et al., 2015). D-glucuronic acid is also present in the backbone and accounts for 5-10\% of the polysaccharide (Geresh \& Arad, 1991; Patel et al., 2013). In addition, sulfate groups are attached to glucose and galactose in the 6 or 3 position, but variable sulfate contents are reported $(1-14 \%$ ) (Arad \& Levy-Ontman, 2010; de Jesus Raposo, de Morais, \& de Morais, 2015). The combination of glucuronic acid and sulfate groups provides anionic characteristics to these polysaccharides, which are responsible for the biotechnological properties as suggested by some authors (de Jesus Raposo et al., 2015; Eteshola, Karpasas, Arad, \& Gottlieb, 1998).

EPMS of Porphyridium sp. show large potential for industrial applications because of their rheological properties. Previous studies reported highly viscous aqueous solutions at relatively low polymer concentrations, comparable to xanthan gum (Eteshola et al., 1998; Geresh \& Arad, 1991). Furthermore, the rheological properties were stable in a wide range of $\mathrm{pH}$ values $(2-9)$ and temperatures $\left(30-60{ }^{\circ} \mathrm{C}\right)$ (Arad et al., 2006). However, contrasting observations were reported by different authors when temperatures were further increased. Whereas Eteshola et al. (1998) observed a strong gelation at temperatures above $60{ }^{\circ} \mathrm{C}$, which was reversible upon cooling, other authors reported the rheological properties to be independent of temperature (Arad et al., 2006; Eteshola et al., 1998; Patel et al., 2013). As such, a clear understanding of the rheological behavior of EPMS from Porphyridium sp. and its temperature dependence is required for commercialization of these polysaccharides towards specific applications.

The rheological properties of Porphyridium sp. polysaccharides are currently only studied for the external part of the cell wall (EPMS). One of the drawbacks limiting the industrial exploitation of Porphyridium sp. extracellular polysaccharides as hydrocolloids is their high production cost, since rather low concentrations of EPMS (below $1.3 \mathrm{~g} / \mathrm{L}$ ) are achieved in the cultivation media (Patel et al., 2013; Singh, Arad, \& 


\section{ACCEPTED MANUSCRIPT}

Richmond, 2000). Therefore, identifying strategies to significantly enhance EPMS production is necessary in order to compete with conventional polysaccharides from plants or macroalgae (Soanen, Da Silva, Gardarin, Michaud, \& Laroche, 2016). For instance, based on the fact that structural polysaccharides form a major part of the residual biomass after extraction of high-value products, characterization of their chemical structure and rheological behavior might improve the economic feasibility of Porphyridium sp. polysaccharides as hydrocolloids. Of particular interest is the bound polysaccharide fraction, further referred to as cell wall polysaccharides (CWPS). If CWPS of Porphyridium sp. would show similar thickening properties as the EPMS, the yield of hydrocolloids would drastically increase, since CWPS make up about $10 \%$ of the Porphyridium sp. biomass (Bernaerts et al., 2018).

The objective of this study is to provide a structural characterization of different cell wall related polysaccharide fractions of $P$. cruentum in relation to their rheological behavior in aqueous polysaccharide suspensions. Four cell wall fractions were isolated from $P$. cruentum, including two extracellular fractions and two cell wall bound fractions. The molecular structure of the polysaccharide extracts was determined, while co-extracted components were also quantified. The rheological properties of the cell wall fractions in aqueous suspensions were studied, including the effect of cations and temperature cycles. The insights provided by this study could indicate the potential of cell wall related polysaccharides of Porphyridium sp. as thickening or gelling agents for food applications.

\section{Materials and Methods}

\subsection{Microalgal biomass}

Lyophilized biomass of Porphyridium cruentum was purchased from Necton (Olhão, Portugal). Information on the cultivation conditions was provided by the company. In short, the microalgae were cultured in Nutribloom Plus ${ }^{\circledR}$ medium in tubular photobioreactors. The photobioreactors were placed outdoor and were subjected to natural sunlight (time of cultivation: June to July 2016). The temperature of the culture was set at $28^{\circ} \mathrm{C}$ and the culture was maintained at $\mathrm{pH} 8$. Biomass was harvested in the late exponential phase using a batch centrifuge and lyophilized to obtain dry biomass. The residual 
moisture content was 3.36\%, determined by vacuum drying as described by Bernaerts et al. (2018). The dry biomass was stored in closed containers at $-80{ }^{\circ} \mathrm{C}$ until use.

\subsection{Extraction of cell wall related polysaccharides}

Different fractions of cell wall related polysaccharides were extracted as described by Bernaerts et al. (2018), with some modifications to scale up the procedure. Four cell wall fractions were obtained: extracellular polymeric substances (EPMS), extracellular polysaccharides (EPS), water soluble cell wall polysaccharides (wsCWPS) and water insoluble cell wall polysaccharides (wiCWPS).

\subsubsection{Extracellular polymeric substances}

Dry biomass $(50 \mathrm{~g})$ was suspended in $2 \mathrm{~L}$ of saline solution $(2.5 \% \mathrm{NaCl}, \mathrm{pH} 7.5)$ and incubated for $16 \mathrm{~h}$ at $25^{\circ} \mathrm{C}$. The suspension was centrifuged $\left(10 \mathrm{~min}, 10000 \mathrm{~g}, 4^{\circ} \mathrm{C}\right)$, the resulting supernatant was again centrifuged $\left(30 \mathrm{~min}, 17000 \mathrm{~g}, 4^{\circ} \mathrm{C}\right.$ ) and cold ethanol was added to the final supernatant to obtain an ethanol concentration above $70 \% \mathrm{v} / \mathrm{v}$. After vacuum filtration, the insoluble residue was dialyzed against demineralized water for $48 \mathrm{~h}$ (Spectra/Por, MWCO $3.5 \mathrm{kDa}$, Spectrum Laboratories, CA, USA), lyophilized (Alpha 2-4 LSC plus, Christ, Osterode, Germany) and denoted as EPMS.

\subsubsection{Extracellular polysaccharides}

Lyophilized EPMS (4 g) was dissolved in $500 \mathrm{~mL}$ of sodium phosphate buffer $(50 \mathrm{mM}$, pH 7.5). Pronase E of Streptomyces sp. (3.5 U/mg, Sigma-Aldrich) was added to achieve $100 \mathrm{U} / \mathrm{g}$ EPMS and the mixture was incubated for $24 \mathrm{~h}$ at $37^{\circ} \mathrm{C}$. Subtilisin A protease of Bacillus licheniformis $(12 \mathrm{U} / \mathrm{mg}$, Sigma-Aldrich) was subsequently added in a ratio of $100 \mathrm{U} / \mathrm{g}$ EPMS and the suspension was incubated for $24 \mathrm{~h}$ at $60^{\circ} \mathrm{C}$. Ethanol was added to the suspensions to achieve a final concentration above $70 \% \mathrm{v} / \mathrm{v}$ and vacuum filtration was applied. The residue was resuspended in acetone and vacuum filtered. The residue was finally dialyzed and lyophilized to obtain EPS.

\subsubsection{Cell wall polysaccharides}

The residual biomass, i.e. the pellets obtained in the two centrifugation steps in section 2.2.1, was resuspended in $1.5 \mathrm{~L}$ demineralized water $(\mathrm{pH} 7)$. Cells were disrupted using high pressure homogenization (Pony NS2006L, Gea Niro Soavi, Düsseldorf, Germany) for 4 passes at 100 MPa. The homogenate (mixture of disrupted cells) was lyophilized and subsequently lipids were removed by 
extraction with $1 \mathrm{~L}$ of hexane:isopropanol $(3: 2)$ for $1.5 \mathrm{~h}$. The solvent was removed by vacuum filtration and this lipid extraction procedure was repeated. Floridean starch was subsequently removed

\subsection{Molecular characterization}

The obtained fractions were characterized for their molecular structure using methods described by Bernaerts et al. (2018) All analyses were performed in triplicate. Briefly, moisture content was determined by vacuum-drying and the average moisture content was taken into account in expressing all components as a percentage of dry matter and in the preparation of aqueous solutions in specific concentrations. Protein content was determined through nitrogen measurement by the Dumas method and estimated using a nitrogen-to-protein conversion factor of 6.25 , assuming that no non-protein nitrogen sourees were present in the isolated cell wall fractions. Ash content was determined gravimetrically after $24 \mathrm{~h}$ at $550^{\circ} \mathrm{C}$. Mineral composition was subsequently determined using inductively coupled plasma optical emission spectrometry (ICP-OES).

Polysaccharides were hydrolyzed into monosaccharides and uronic acids using methanolysis combined with trifluoroacetic acid hydrolysis, and subsequently analyzed by high performance anion exchange chromatography combined with pulsed amperometric detection (HPAEC-PAD) using the exact conditions as described by Bernaerts et al. (2018). Monosaccharide standards were subjected to the 
same hydrolysis conditions in order to correct for sugar degradation during the acid hydrolysis. It was validated that HPAEC-PAD as applied in our previous study (Bernaerts et al., 2018) resulted in accurate quantification of uronic acids, by comparison with the colorimetric method of Blumenkrantz \& Asboe-Hansen, (1973). Sulfate groups were quantified using the barium chloride-gelatin method of Dodgson \& Price (1962).

The molecular weight distribution of the polymers was determined according to Kyomugasho, Willemsen, Christiaens, Van Loey, \& Hendrickx, (2015). High performance size exclusion chromatography (HPSEC) was used, equipped with multi-angle laser light scattering (MALLS, PN3621, Postnova Analytics, Landsberg am Lech, Germany), a refractive index (RI) detector (Shodex RI-101, Showa Denko K.K., Kawasaki, Japan), a diode array detector (DAD, G1316A, Agilent Technologies, Diegem, Belgium) and a viscometer (Postnova Analytics, Landsberg am Lech, Germany). MES buffer (0.1 M of 2-(N-morpholino)ethanesulfonic acid, $\mathrm{pH} 7$, containing $0.1 \mathrm{M} \mathrm{NaCl})$ was filtered through a $0.1 \mu \mathrm{m}$ filter and used as the eluent. Samples were dissolved in the eluent $\left(2 \mathrm{mg} / \mathrm{mL}\right.$ ) for $48 \mathrm{~h}$ and filtered through $0.45 \mu \mathrm{m}$ syringe filters (Millex ${ }^{\circledR}-\mathrm{HV}$, Merck Millipore Ltd, Cork, Ireland) prior to analysis. Exactly $100 \mu \mathrm{L}$ of sample was injected onto a series of Waters columns (Waters, Milford, MA, USA): Ultrahydrogel 250, 1000 and 2000 with exclusion limits of $8 \times 10^{4}$, $4 \times 10^{6}$ and $1 \times 10^{7} \mathrm{~g} / \mathrm{mol}$, respectively. Samples were eluted at $40^{\circ} \mathrm{C}$ using a flow rate of $0.5 \mathrm{~mL} / \mathrm{min}$. The molecular weight was calculated using the $2^{\text {nd }}$ order Debye fitting method with Nova Mals software (version 1.0.0.18, Postnova Analytics, Landsberg am Lech, Germany), using a dn/dc value of $0.146 \mathrm{~mL} / \mathrm{g}$, which is within the range of $\mathrm{dn} / \mathrm{dc}$ values for polysaccharides in aqueous buffers $(0.140-0,160 \mathrm{~mL} / \mathrm{g})($ Harding, 2005).

\subsection{Rheological characterization}

\subsubsection{Preparation of suspensions}

Lyophilized fractions were suspended overnight in ultrapure water (organic free, $18 \mathrm{M} \Omega \mathrm{cm}$ resistance) in a concentration of $2 \% \mathrm{w} / \mathrm{w}$. Suspensions were then homogenized for $5 \mathrm{~min}$ at $8000 \mathrm{rpm}$ (Ultra-Turrax T25, Janke \& Kunkel GmbH, Staufen, Germany) and again stirred overnight to ensure complete hydration of the $P$. cruentum fractions. It was validated that the homogenization step did not 


\section{ACCEPTED MANUSCRIPT}

affect the rheological properties of the samples, while it allowed the reduction of the measuring gap, since non-hydrated particles were avoided as analyzed by laser diffraction (data not shown). Moreover, no changes in molecular properties were expected due to the homogenization step, as it was previously shown that the molecular weight of pectin polymers was not altered by application of high pressure homogenization using pressures up to $50 \mathrm{MPa}$ (Shpigelman, Kyomugasho, Christiaens, Van Loey, \& Hendrickx, 2015).

The effect of additional cations on the rheological properties was investigated for suspensions of EPS and wsCWPS. Suspensions were prepared by addition of $0.2 \mathrm{M} \mathrm{NaCl}, \mathrm{KCl}$ or $\mathrm{CaCl}_{2}$ to achieve a final concentration of $2 \% \mathrm{w} / \mathrm{w}$ and stoichiometric ratios of $\mathrm{R} \geq 1$, with $R=\frac{\left[\mathrm{Na}^{+} \mathrm{or} \mathrm{K}^{+}\right]}{\left[\mathrm{COO}^{-}\right]+\left[\mathrm{SO}_{3}^{-}\right]}$for monovalent cations and $R=\frac{2\left[\mathrm{Ca}^{2+}\right]}{\left[\mathrm{COO}^{-}\right]+\left[\mathrm{SO}_{3}^{-}\right]}$for divalent cations, irrespective of the intrinsic ions present in the samples. The $\mathrm{pH}$ of the suspensions was between 7.3 and 7.6, ensuring that the carboxylic and sulfate groups were negatively charged.

Prior to rheological analyses, stability of the suspensions was checked using a Turbiscan MA 2000 (Formulaction, L'Union, France). Since suspensions of wiCWPS showed significant sedimentation within $30 \mathrm{~min}$, no rheological analyses were performed for this fraction. All other fractions resulted in stable suspensions.

\subsubsection{Rheological measurements}

Rheological analyses were performed using a stress-controlled rheometer (MCR 302, Anton Paar, Graz, Austria). A parallel plate geometry (PP25, diameter $25 \mathrm{~mm}$ ) was used as a measuring system for suspensions of EPMS and EPS, with a measuring gap set at $1 \mathrm{~mm}$. For the low viscous wsCWPS suspensions, a double wall Couette geometry (DG26.7, internal diameter $12.3 \mathrm{~mm}$, external diameter $13.3 \mathrm{~mm}$ and measuring height $40 \mathrm{~mm}$ ) was used. Samples were presheared for $30 \mathrm{~s}$ at a shear rate of $20 \mathrm{~s}^{-1}$ followed by $300 \mathrm{~s}$ of rest before each measurement. To ensure reliability of the obtained data, a minimum torque limit was fixed at $0.1 \mu \mathrm{N} \cdot \mathrm{m}$.

The flow behavior was studied using steady-shear measurements, by logarithmically increasing shear rate from 0.1 to $100 \mathrm{~s}^{-1}$ and applying each shear rate for $20 \mathrm{~s}$. To determine the viscoelastic properties, 


\section{ACCEPTED MANUSCRIPT}

strain sweep measurements were performed by increasing the shear strain logarithmically from 0.01 to $1000 \%$, at a constant angular frequency of $10 \mathrm{rad} / \mathrm{s}$. In frequency sweep tests, the angular frequency was decreased logarithmically from 100 to $0.1 \mathrm{rad} / \mathrm{s}$, at a constant shear strain of $2 \%$ within the linear viscoelastic region. All measurements were performed at $25{ }^{\circ} \mathrm{C}$.

Temperature sweeps were performed for suspensions of EPS and wsCWPS, with and without the addition of cations. For these measurements, the parallel plate geometry (PP25) was also used for wsCWPS suspensions, but with a measuring gap of $0.5 \mathrm{~mm}$. Samples were heated from 20 to $80{ }^{\circ} \mathrm{C}$ at a heating rate of $2{ }^{\circ} \mathrm{C} / \mathrm{min}$, followed by a holding time of $10 \mathrm{~min}$ at $80^{\circ} \mathrm{C}$, prior to cooling to $20^{\circ} \mathrm{C}$ at a rate of $2{ }^{\circ} \mathrm{C} / \mathrm{min}$. To prevent evaporation during the measurement, the sample surface was covered with light paraffin oil and a solvent trap was installed. Storage modulus $\left(G^{\prime}\right)$ and loss modulus $\left(G^{\prime \prime}\right)$ were monitored at a constant angular frequency of $10 \mathrm{rad} / \mathrm{s}$ and a constant shear strain of $5 \%$, within the linear viscoelastic region.

\subsection{Statistical analysis}

The composition and molecular characterization of the cell wall fractions was determined in triplicate and the data obtained presented as the average of three measurements \pm standard error. Differences in average values were statistically analyzed using one-way ANOVA combined with Tukey's test for multiple comparison $(\mathrm{P}<0.05)$ with JMP statistical software (JMP Pro 12, Cary, NC, USA). Frequency sweep curves were fitted to rheological models using non-linear regression with SAS statistical software (SAS 9.4, Cary, NC, USA). The estimated model parameters were statistically compared by use of $95 \%$ confidence intervals.

\section{Results and discussion}

\subsection{Chemical composition of the cell wall fractions}

Four cell wall fractions were isolated from lyophilized P. cruentum biomass, including two extracellular and two cell wall bound fractions. The extraction yield of the different fractions is presented in Fig. 1. First, it should be noted that the extraction procedures were performed on lyophilized biomass, implying that 


\section{ACCEPTED MANUSCRIPT}

(part of) the extracellular polymers which were secreted into the cultivation medium have not been recovered during harvesting of the biomass. As a consequence, the yield of EPMS and EPS obtained in the current study might be lower than when directly extracted from wet biomass or the cultivation medium. Furthermore, the growth conditions were not optimized for polysaccharide production. Nevertheless, the presence of unsecreted extracellular layers surrounding the harvested cells was confirmed like in our previous study (Bernaerts et al., 2018). The isolated cell wall fractions contributed for one third of the weight of the dried biomass. About $70 \%$ of the cell wall related polysaccharides remained bound to the cell wall, i.e. the sum of wsCWPS and wiCWPS, which is in agreement with previously reported values (Arad \& Levy-Ontman, 2010).

Fig. 1 Yield of different fractions isolated from dry biomass of P. cruentum, expressed as a weight percentage of dry biomass (\%) (EPMS: extracellutar polymeric substances; EPS: extracellular polysaccharides; wsCWPS: water soluble cell wall polysaccharides; wiCWPS: water insoluble cell wall polysaccharides).

The chemical composition of the isolated cell wall fractions is shown in Fig. 2. Polysaccharides, i.e. the sum of monosaccharides, uronic acids and sulfate esters, presented less than half of the isolated fractions, with proteins and ash making up a large part of the fractions except for wsCWPS. It has been previously reported that the use of traditional alcohol precipitation for the extraction of Porhyridium sp. exopolysaccharides resulted in low purified polymers with high salt content (Patel et al., 2013). Even though protease treatments and dialysis steps were included in this extraction procedure to remove proteins and minerals, respectively, substantial amounts of these components were co-extracted. Further 


\section{ACCEPTED MANUSCRIPT}

purification of the cell wall fractions might therefore be desired, as this might improve their solubility and rheological properties (Patel et al., 2013).

Fig. 2 Chemical composition of different fractions isolated from P. cruentum (EPMS: extracellular polymeric substances; EPS: extracellular polysaccharides; wsCWPS: water soluble cell wall polysaccharides; wiCWPS: water insoluble cell wall polysaccharides).

The use of saline solution for extraction of extracellular polymers resulted in an EPMS fraction mainly rich in proteins. Although a glycoprotein has been described in the extracellular matrix of Porphyridium sp., proteins generally only represent about $5 \%$ of the dry weight of the extracellular polymers (Arad \& LevyOntman, 2010; Gloaguen et al., 2004). In the current study, the high protein content in this fraction might be a result of co-extraction of phycobiliproteins, water-soluble pigments providing a red color to this fraction. Even though these pigments are stored in the phycobilisome inside the cell, Marcati et al. (2014) reported the co-extraction of extracellular polysaccharides and B-phycoerythrin in absence of an intense cell disruption step (Marcati et al., 2014). The use of two broad-spectrum proteases led to the removal of $80 \%$ of the proteins, resulting in the EPS fraction. A higher contribution of ash was observed in this fraction, probably resulting from buffer salts during the protease treatment which were not completely removed by dialysis. It should be noted that the reported protein contents are probably an overestimation, since the traditional nitrogen-to-protein conversion factor of 6.25 was used, assuming that non-protein 


\section{ACCEPTED MANUSCRIPT}

nitrogen sources were not extracted or completely removed by dialysis. Since the amount of minerals was remarkably high in these fractions, it is expected that the removal of smaller molecules during dialysis was impeded, probably due to the viscous behavior of these cell wall fractions. The incomplete removal of nonprotein nitrogen sources might therefore result in an overestimation of the protein contents in all fractions. Next to the extracellular fractions, CWPS were obtained and fractionated using a hot waterfractionation. Most of the CWPS were soluble in hot water, as wsCWPS accounted for $76 \%$ of the total CWPS weight. Moreover, this fraction was the purest fraction obtained, with low amounts of ash and proteins. In contrast, wiCWPS only presented $10 \%$ of polysaccharides and was mainly composed of residual proteins and ash after the extraction.

Since substantial amounts of ash were observed in most cell wall fractions, the composition of minerals was also analyzed. The amounts of mono- and divalent cations present in the different cell wall fractions are shown in Fig. 3. In fact, the presence of intrinsic minerals might influence the physicochemical properties of polysaccharide suspensions, as specific cations play an important role in the stabilization of electrostatic repulsions and in the gelation of negatively charged polysaccharides (Beckett, 2012). Both extracellular fractions mainly contained the divalent cations calcium and magnesium. Moreover, an increased sodium content was observed for EPS, resulting from the phosphate buffers used in the protease treatment. While low mineral amounts were observed for wsCWPS, the high ash content in wiCWPS was largely due to calcium and iron, which were probably strongly bound to the polysaccharides in the wiCWPS

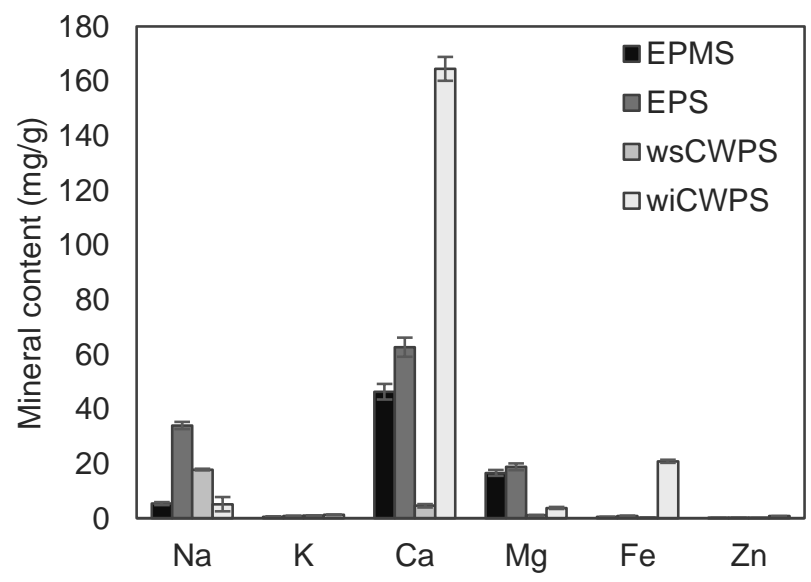


Fig. 3 Mineral composition of different fractions isolated from P. cruentum (EPMS: extracellular polymeric substances; EPS: extracellular polysaccharides; wsCWPS: water soluble cell wall polysaccharides; wiCWPS: water insoluble cell wall polysaccharides).

\subsection{Molecular characterization of the cell wall related polysaccharides}

The polysaccharides in the different fractions were characterized in terms of monosaccharide and uronic acid composition, sulfate ester content and molecular weight distribution. The monosaccharide and uronic acid profiles are presented in Fig. 4. All fractions were mainly composed of galactose, glucose, xylose and glucuronic acid. These sugars were previously reported by several authors as the main constituents in extracellular polysaccharides of Porphyridium sp. in similar ratios (Geresh et al., 2009, 2002; Patel et al., 2013). Interestingly, wsCWPS showed exactly the same monosaccharide profile as the extracellular fractions, while a different ratio of galactose and xylose was observed in wiCWPS. This suggests that the difference in solubility of extracellular and bound polysaccharides is not related with the monosaccharide composition. Although the same monosaccharides were present in all fractions, they might be differently organized into polysaccharide chains with a distinct molecular structure, possibly resulting in different solubilities. Meanwhile, differences in sulfate ester groups were observed among the different samples. In Fig. 2, sulfate groups are presented as a weight percentage of each fraction. However, as the yield of polysaccharide largely differed for all fractions, the molar ratios of sulfate groups to monosaccharides and uronic acids might be a better comparison. A larger ratio was observed for EPMS (0.23) compared to wsCWPS (0.18). In other words, whereas one out of four monosaccharide residues in the extracellular fraction is sulfated, only one out of five monosaccharides contains a sulfate group in wsCWPS. In fact, it was previously reported that as the sulfate content of Porphyridium sp. polysaccharides increased, their solubility in $\mathrm{NaCl}$ solutions increased (Geresh, Lupescu, \& Arad, 1992). Although sulfate contents of $4-14 \% \mathrm{w} / \mathrm{w}$ are generally found in literature for Porphyridium sp. extracellular polysaccharides (de Jesus Raposo et al., 2015; Geresh \& Arad, 1991), several reports did not specify the purity of the isolated fractions and might therefore underestimate the amount of sulfated sugar residues. 


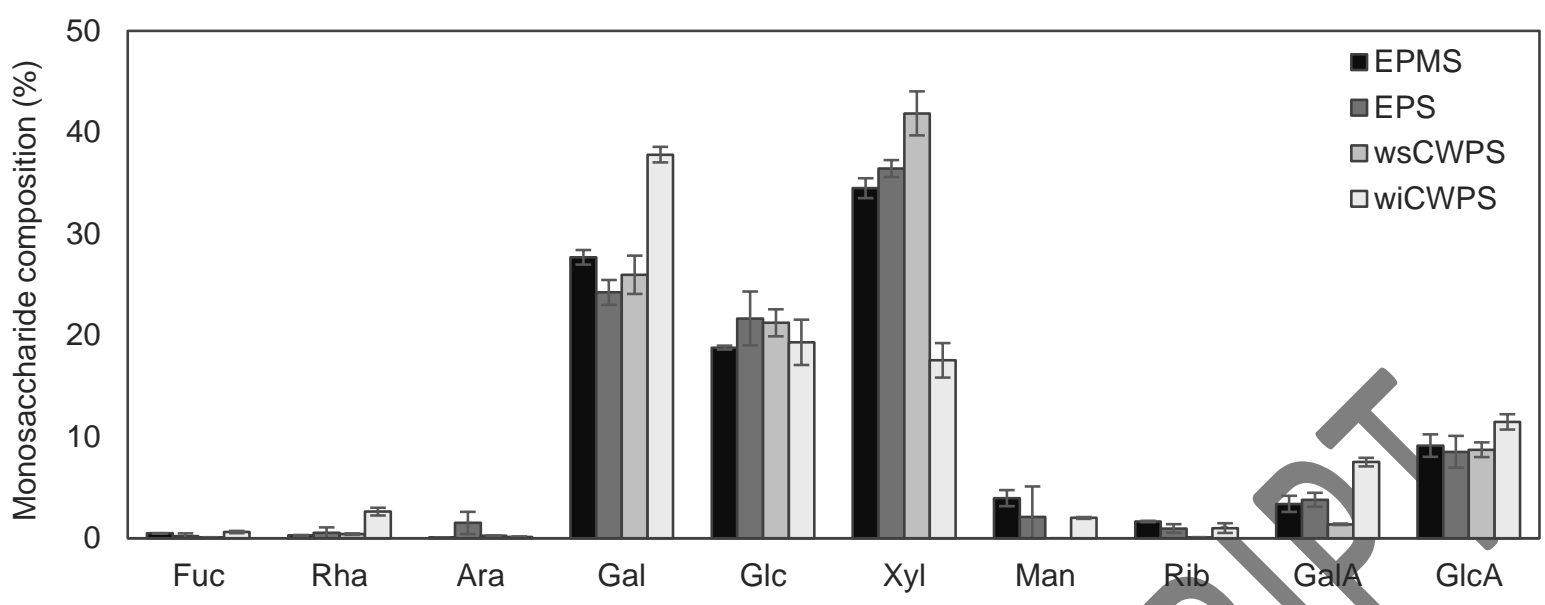

Fig. 4 Monosaccharide and uronic acid composition in different fractions of $P$. cruentum, expressed as a percentage of total monosaccharides and uronic acids (\%). (EPMS: extracellular polymeric substances; EPS: extracellular polysaccharides; wsCWPS: water soluble cell wall polysaccharides; wiCWPS: water insoluble cell wall polysaccharides)

The molecular weight distributions of the polymers in the different cell wall fractions are presented in Fig. 5. Results of wiCWPS are not shown due to a very low recovery, since a large part of the sample was retained in the filtration step prior to HPSEC-analysis. High recoveries were obtained for the other cell wall fractions, being 75.6\% for EPMS, 75.2\% for EPS and 89.2\% for wsCWPS. It is clear from Fig. 5 that similar elution profiles were observed for the two extracellular fractions, with two populations of larger polymers eluting between 32 and 50 min with peak maxima at $\sim 35$ and $41 \mathrm{~min}$, and three populations of smaller compounds eluting after $60 \mathrm{~min}$. From the UV absorbance at $280 \mathrm{~nm}$, it was inferred that the populations of larger polymers were only composed of polysaccharides, whereas proteins were present in the fraction eluting after $60 \mathrm{~min}$. In this region, the UV absorbance was clearly lower for EPS compared to EPMS, confirming the successful removal of substantial amounts of proteins by the protease treatment. The weighted-average molecular weight was determined using data between 32 and 50 min, since compounds eluting after $60 \mathrm{~min}$ are not expected to be polymers (Jamsazzadeh Kermani, Shpigelman, Bernaerts, Van Loey, \& Hendrickx, 2015). Comparable molecular weight distributions were observed for both extracellular fractions, with weighted-average molecular weights of $1.70 \times 10^{6} \mathrm{~g} / \mathrm{mol}$ and $1.40 \times 10^{6}$ g/mol for EPMS and EPS, respectively. These values are in the same order of magnitude as reported by Geresh, Adin, Yarmolinsky, \& Karpasas, (2002). The molar mass profiles (slanting lines) showed a very small slope, suggesting populations of polymers with a similar molecular weight but a distinct 


\section{ACCEPTED MANUSCRIPT}

hydrodynamic volume, as concluded from the different elution times. The same observation was made by the abovementioned authors and they ascribed it to aggregation of polysaccharide molecules preventing size separation (Geresh et al., 2002). In general, both extracellular fractions possessed high molecular weight polysaccharides, which could give rise to interesting physicochemical properties.

A different elution profile was observed for wsCWPS, showing a unimodal distribution of large polymers eluting between 36 and $50 \mathrm{~min}$ with peak maxima at $42 \mathrm{~min}$, indicating that the hydrodynamic volume of wsCWPS polymers is smaller compared to those in the extracellular fractions. Moreover, a steady decrease in molecular weight with increasing elution time was observed for this fraction, indication that a larger hydrodynamic volume was related with a larger molecular weight. The higher concentration of polymers eluting at $36-50$ min can be ascribed to the higher contribution of polysaccharides together with low amounts of proteins or ash in this fraction, as previously mentioned. The presence of proteins, although limited, was evidenced by a small UV absorbance peak in this region. A weighted-average molecular weight of $0.75 \times 10^{6} \mathrm{~g} / \mathrm{mol}$ was observed for wsCWPS, being significantly smaller $(\mathrm{P}<0.05)$ than that of the extracellular fractions. This is interesting given that the wsCWPS fraction exhibited a similar monosaccharide profile as the extracellular fractions, and suggests distinct molecular organization of these sugars into polysaccharide chains compared to the extracellular fractions. 


\section{ACCEPTED MANUSCRIPT}
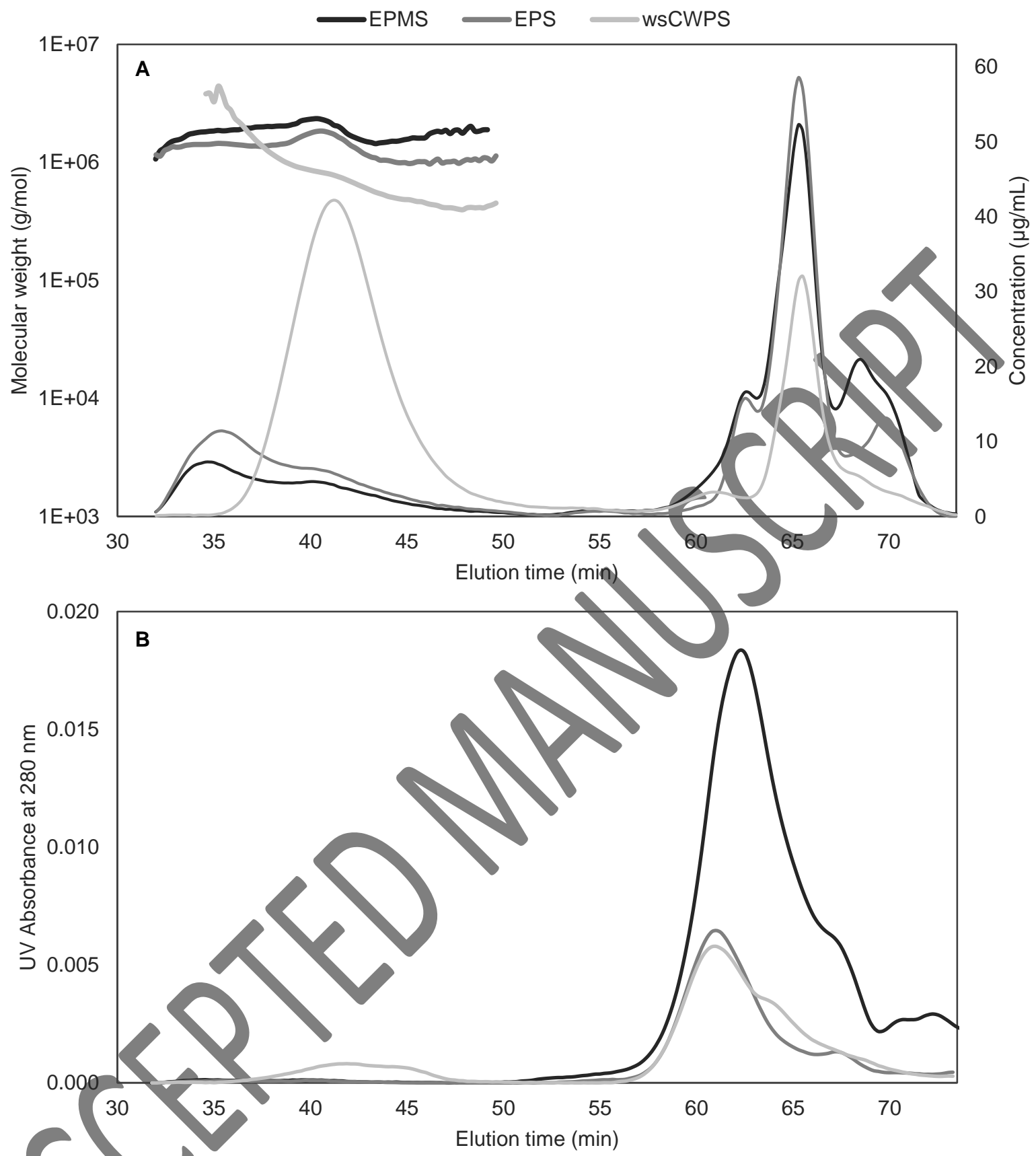

Fig. 5 Molecular weight distribution of polymers in different fractions isolated from P. cruentum (EPMS: extracellular polymeric

The use of a viscosity detector attached to the HPSEC-MALLS allowed quantification of the intrinsic viscosity of the eluting polymers. No significant differences were observed between the intrinsic viscosity of both extracellular fractions, being $46.62 \pm 3.06 \mathrm{dL} / \mathrm{g}$ for EPMS and $50.62 \pm 1.37 \mathrm{dL} / \mathrm{g}$ for EPS. Since the removal of proteins did not influence the intrinsic viscosity, the viscous behavior can be largely ascribed 
to the polysaccharides in these fractions. The results obtained in this study are somewhat higher than previously reported values for extracellular polysaccharides of Porphyridium sp. $(20.9-42 \mathrm{dL} / \mathrm{g})$

\subsection{Rheological characterization of the suspensions}

The potential of the obtained cell wall fractions as thickening or gelling agents was investigated through rheological analyses. The flow behavior of $2 \% \mathrm{w} / \mathrm{w}$ suspensions of the cell wall fractions is presented in Fig. 6. Both extracellular fractions (EPMS and EPS) showed shear-thinning flow behavior, i.e. the viscosity decreased with increasing shear rate. Even though the amount of polysaccharides was rather low in these fractions (Section 3.1), the critical overlap concentration was exceeded in the $2 \% \mathrm{w} / \mathrm{w}$ suspensions, indicating physicalentanglement of the polysaccharides (Saha \& Bhattacharya, 2010). As the critical concentration is related with the intrinsic viscosity, and thus with the molecular weight of the polymers, a low critical overlap concentration was indeed expected for the high molecular weight polymers in the extracellular fractions. Shear-thinning behavior was previously reported by several authors for $1 \%$ polysaccharide solutions (Eteshola et al., 1998; Geresh et al., 2002; Liberman, Ochbaum, Arad, \& Bitton, 2016). Moreover, suspensions of EPS showed a higher viscosity and a larger shear-thinning degree compared to EPMS. This indicates a higher initial degree of system entanglement (weak network) in the EPS suspension, which is lost when applying higher shear forces. In this context, removal of the proteins resulted in increased thickening properties, indicating that the viscous behavior can be ascribed to the 


\section{ACCEPTED MANUSCRIPT}

polysaccharides in this sample. As a consequence, increasing the purity of the extracellular fractions will probably result in a further increase of the viscosity. Surprisingly, the suspensions of wsCWPS presented Newtonian flow behavior, implying that the critical overlap concentration was not reached and no polymerpolymer interactions were formed in this suspension. Therefore, even though the polysaccharides in wsCWPS exhibited a relatively high weighted-average molecular weight and an appreciable intrinsic viscosity, a higher concentration of this fraction is needed to induce thickening in aqueous solutions.

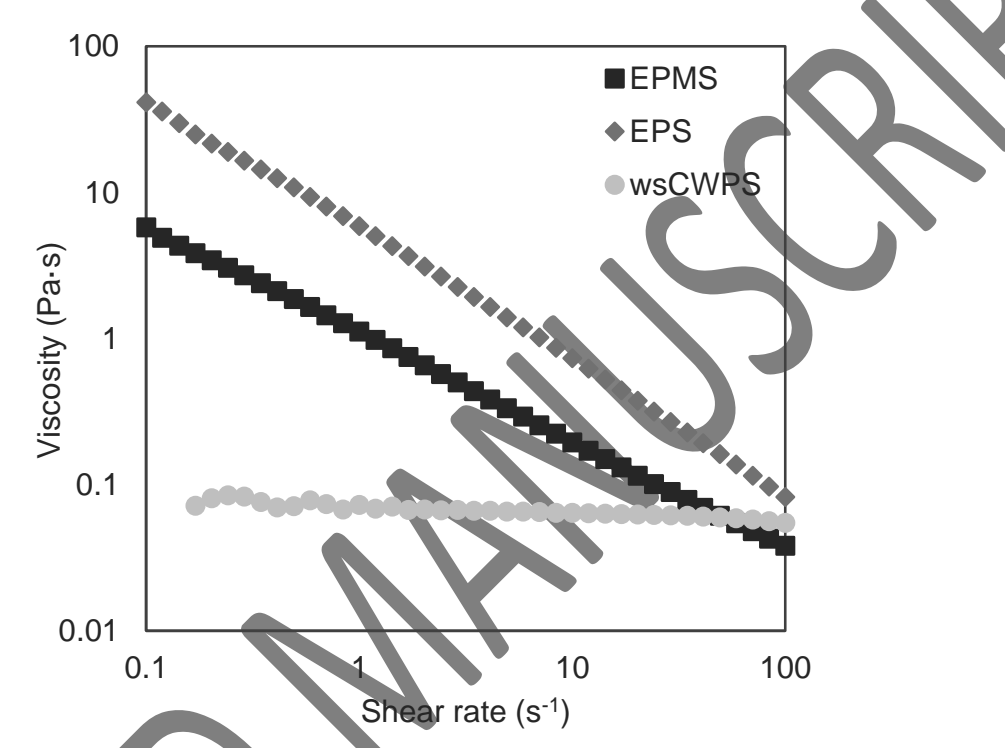

Small deformation oscillatory measurements were applied to gain insight into the network structure of the suspensions, with strain sweep and frequency sweep curves shown in Fig. 7A and 7B, respectively. A large

Fig. 6 Flow curves of suspensions (2\% w/w) of different fractions of P. cruentum (EPMS: extracellular polymeric substances; EPS: extracellular polysaccharides; wsCWPS: water soluble cell wall polysaccharides). Only data points with reliable torque values $(>0.1 \mu \mathrm{N} \cdot \mathrm{m})$ are shown. linear viscoelastic region was observed from the strain sweep curves of the extracellular fractions, both showing a critical strain above 50\%. In addition, predominant elastic behavior was observed, since values for the storage modulus $\left(G^{\prime}\right)$ exceeded those of the loss modulus $\left(G^{\prime \prime}\right)$ in this region. This elastic behavior was more pronounced for EPS compared to EPMS. In contrast, viscous behavior was observed for wsCWPS, with a constant loss modulus and $G^{\prime}<G^{\prime \prime}$ over the whole range of shear strains explored. 

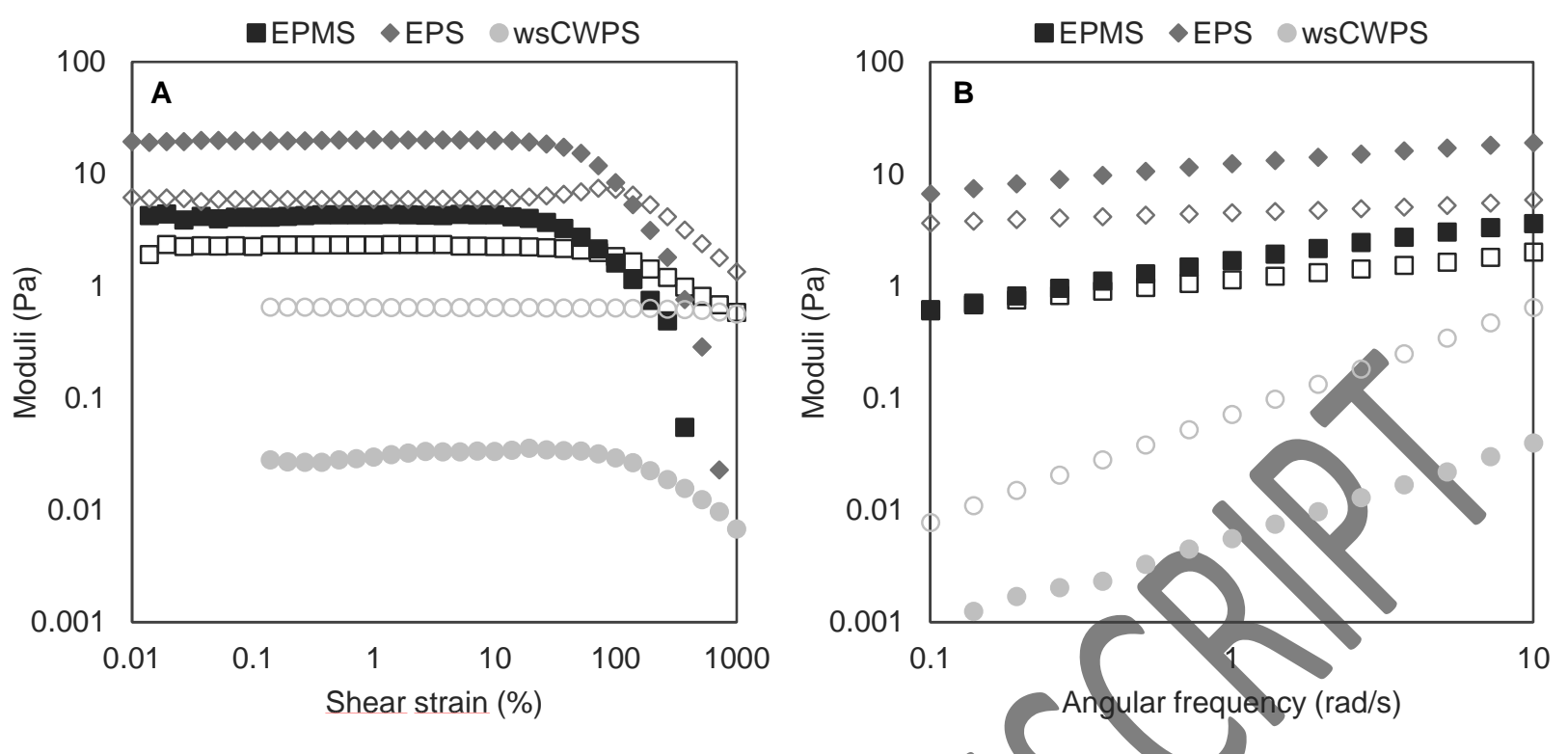

Fig. 7 Strain sweep curves (A) and frequency sweep curves (B) of suspensions ( $2 \% \mathrm{w} / \mathrm{w})$ of different fractions from P. cruentum (EPMS: extracellular polymeric substances; EPS: extracellular polysaccharides; wsCWPS: water soluble cell wall polysaccharides). Strain sweeps were performed at a constant angular frequency of $10 \mathrm{rad} / \mathrm{s}$. Frequency sweeps were determined at a constant shear strain of $2 \%$, within the linear viscoelastic region. Storage moduli $\left(G^{\prime}\right)$ are shown as filled symbols, loss moduli $\left(G^{\prime \prime}\right)$ as empty symbols. Only data points with reliable torque values $(\nabla 0.1 \mu \mathrm{N} \cdot \mathrm{m})$ are shown.

To determine the frequency dependence of the moduli, data of the frequency sweeps were fitted by a power law model:

(Eq. 1)

(Eq. 2)

with $\omega$ the angular frequency $(\mathrm{rad} / \mathrm{s})$ and $a, b, c$ and $d$ model parameters. Parameters $a$ and $b$ provide insight into the strength of the network, whereas parameters $c$ and $d$ describe the gel behavior (Larson, 1999). The estimated model parameters for the different fractions are presented in Table 1. Limited gel behavior was observed for the EPMS suspension. Even though the frequency dependency was rather low (parameter $c<0.5$ ), the ratio of $G^{\prime \prime} / G^{\prime}$ indicates no dominant elastic behavior, as also observed from similar values for parameters $a$ and $b$. In contrast, removal of proteins led to a more gel-like structure in EPS, as parameters $c$ and $d$ further decreased. Moreover, the strength of the network largely increased, with parameter $a$ almost ten times higher compared to the EPMS suspension. The network cannot be considered as a true gel, which would be characterized by a clear independence of the angular frequency $\left(G^{\prime} \propto G^{\prime \prime} \propto \omega^{0}\right)$ and a ratio of $G^{\prime \prime} / G^{\prime}$ in the order of $10^{-2}$. Instead, the EPS suspension showed a behavior 
of a weak gel, describing systems falling between covalently crosslinked materials and entanglement networks. In a weak gel, polymer chains are typically physically crosslinked into networks, but the

Finally, attempts were made to improve the rheological properties, since several hydrocolloids require crosslinks are of small finite energy and/or finite lifetime (Kavanagh \& Ross-Murphy, 1998; Lizarraga, De Piante Vicin, González, Rubiolo, \& Santiago, 2006). In contrast to the structured EPS suspension, wsCWPS presented typical behavior of a viscoelastic fluid, with $G^{\prime} \propto \omega^{2}$ and $G^{\prime \prime} \propto \omega^{1}$. Moreover, the value of parameter $a$ was even approaching 0, implying that no elastic behavior was exhibited by this suspension (Lizarraga et al., 2006). This corresponds to the observed flow behavior of an ideal Newtonian viscous fluid (Fig. 6). In other words, no physical crosslinks or entanglements of wSCWPS polymers occurred in the $2 \% \mathrm{w} / \mathrm{w}$ suspension, indicating the limited potential of this fraction as a thickening or gelling agent.

Table 1 Parameters a, b, c and d ( \pm standard error) of the power law models $\left(G^{\prime}=a \cdot \omega^{c}\right.$ and $\left.G^{\prime \prime}=b \cdot \omega^{d}\right)$ fitted to the storage modulus $\left(G^{\prime}\right)$ and loss modulus $\left(G^{\prime \prime}\right)$ as a function of the angular frequency $(\omega)$. Suspensions of different fractions isolated from $P$. cruentum were prepared at a concentration of $2 \% \mathrm{w} / \mathrm{w}$ (EPMS: extracellular polymeric substances; EPS: extracellular polysaccharides; wsCWPS: water soluble cell wall polysaccharides). The estimated values of the model parameters were compared statistically by use of $95 \%$ confidence intervals. All values were significantly different.

\begin{tabular}{lcccc} 
& $\mathbf{a}$ & $\mathbf{b}$ & $\mathbf{c}$ & $\mathbf{d}$ \\
\hline EPMS & $1.63 \pm 0.02$ & $1.12 \pm 0.01$ & $0.36 \pm 0.01$ & $0.24 \pm 0.01$ \\
EPS & $11.93 \pm 0.07$ & $4.52 \pm 0.02$ & $0.21 \pm 0.01$ & $0.10 \pm 0.01$ \\
wsCWPS & $0.0004 \pm 0.0003$ & $0.06 \pm 0.01$ & $1.64 \pm 0.15$ & $1.00 \pm 0.01$ \\
\hline
\end{tabular}

cations or heating-cooling cycles to induce gelation. In fact, the three main mechanisms proposed for gelation of hydrocolloids are ionotropic gelation (typically cation-mediated gelation), cold-set gelation and heat-set gelation. The latter mechanism consists of heating a hydrocolloid dispersion to induce gelation, typically by unfolding or expansion of starch and proteins into an arranged network, but is also known for some polysaccharide systems such as konjac glucomannan and methyl cellulose. In contrast, cold-set gelation requires cooling of a warm hydrocolloid dispersion to form inter-chain helices, resulting in a stable three dimensional network. Typical examples of such hydrocolloids are agar and gelatin (Saha \& Bhattacharya, 2010). Temperature sweeps of EPS and wsCWPS suspensions are presented in Fig. 8, showing the storage and loss moduli during the heating, holding and cooling phases. Given that no drastic 


\section{ACCEPTED MANUSCRIPT}

changes in gelling behavior were observed during the heating-cooling cycles, it was concluded that cold-

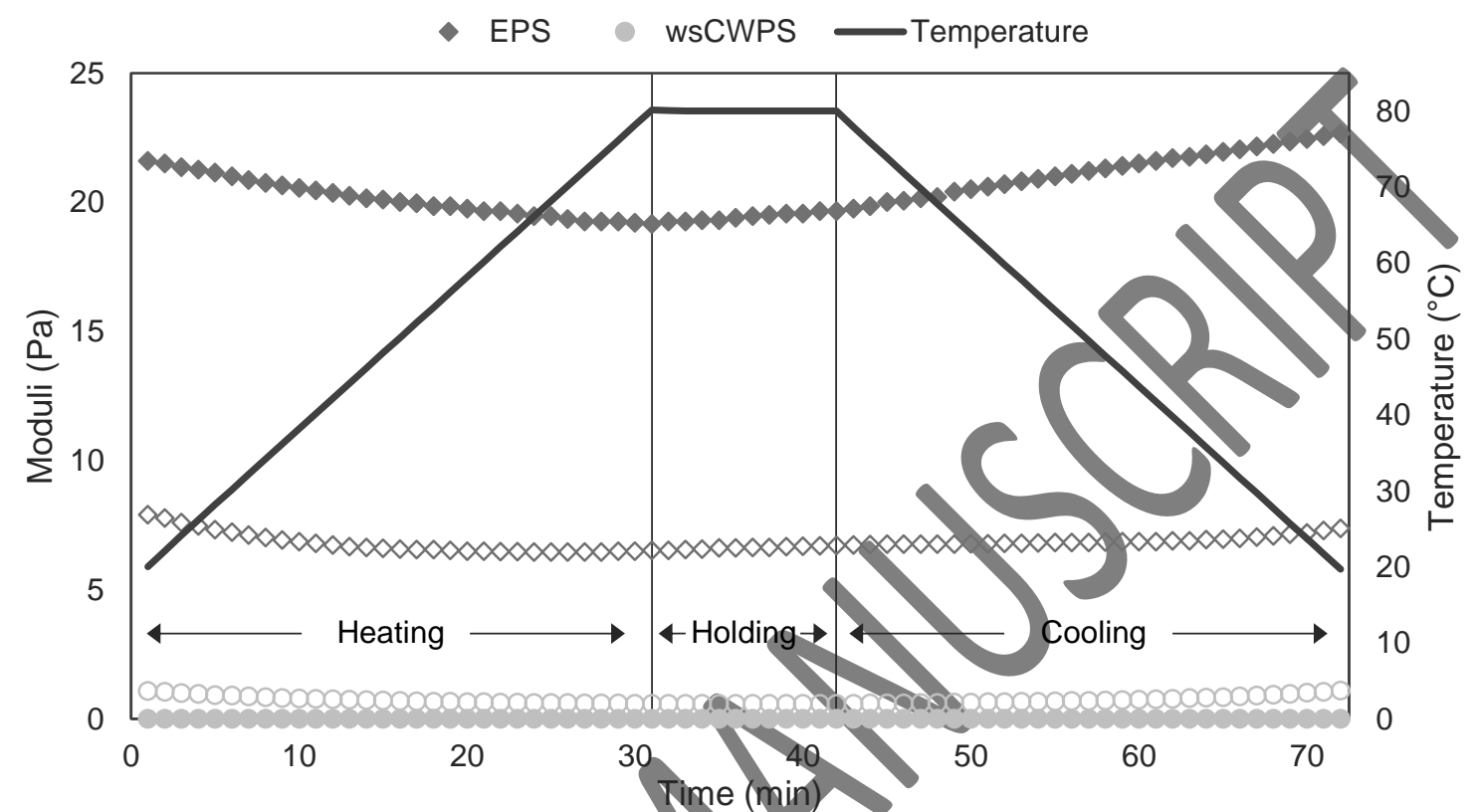

Fig. 8 Temperature sweeps of suspensions ( $2 \% \mathrm{w} / \mathrm{w}$ ) of different fractions of $P$. cruentum (EPS: extracellular polysaccharides; wsCWPS: water soluble cell wall polysaccharides). Temperature was increased from 20 to $80{ }^{\circ} \mathrm{C}\left(2{ }^{\circ} \mathrm{C} / \mathrm{min}\right)$, kept constant at $80^{\circ} \mathrm{C}$ for $10 \mathrm{~min}$, and cooled from 80 to $20^{\circ} \mathrm{C}\left(2{ }^{\circ} \mathrm{C} / \mathrm{min}\right)$. Storage modulus ( $G^{\prime}$, filled symbols) and loss modulus $\left(G^{\prime \prime}\right.$, empty symbols) were determined at a constant angular frequency of $10 \mathrm{rad} / \mathrm{s}$ and a constant shear strain of $5 \%$, within the linear viscoelastic region.

To investigate possible gelation through a cation mediated gelation mechanism, suspensions were prepared in presence of different cations $\left(\mathrm{Na}^{+}, \mathrm{K}^{+}\right.$and $\left.\mathrm{Ca}^{2+}\right)$. This was based on the fact that distinct hydrocolloids such as carrageenans, alginates and pectins require different cations for successful gelation (Imeson, 1997, 2011, Saha \& Bhattacharya, 2010). In the current study, no increases in viscosity or viscoelastic moduli were observed for any of the fractions in presence of different cations, either with or without heatingcooling cycles (data not shown). Eteshola et al. (1998) even reported a decreased viscosity in presence of $\mathrm{NaCl}, \mathrm{KCl}$ or $\mathrm{CaCl}_{2}$, however, highly concentrated electrolyte solutions were used in that study (Eteshola et al., 1998). Liberman et al. (2016) reported that the addition of $\mathrm{Zn}^{2+}$ only led to screening of negative charges of the polysaccharides, resulting in a slight viscosity increase, but did not lead to any network formation. The authors concluded that a low concentration of $\mathrm{Zn}^{2+}(250 \mathrm{ppm})$ was sufficient to screen most of these charges, while further addition of ions did not affect the viscosity (Liberman et al., 2016). In the 
current study, intrinsic cations were present in high amounts in all cell wall fractions (Fig. 3), implying that additional cations probably did not play a role in the screening of electrostatic repulsions of negatively charged carboxylic groups or sulfate groups of the polysaccharide chains, as no changes in viscosity were observed. However, removal of intrinsic cations and additional rheological measurements of suspensions

\section{Conclusions}

Different cell wall fractions, including two extracellular fractions and two fractions containing CWPS, were successfully obtained from the red microalga Porphyridiumcruentum. The extracellular polysaccharides were characterized by a population of high molecular weight polymers with high intrinsic viscosities. Even though wsCWPS exhibited the same monosaccharide composition as the extracellular fractions, the sugar residues in the former were probably differently organized into polysaccharide chains, resulting in polymers with lower molecular weights and lower intrinsic viscosities. These differences in polysaccharide characteristics resulted in distinct rheological properties. Whereas polysaccharide solutions of EPS displayed high viscosities and a weak gel structure, wsCWPS suspensions exhibited a Newtonian flow behavior. As a consequence, wsCWPS of Porphyridium sp. showed limited potential as a thickening agent for food applications. However, further research on their potential as bioactive compounds might be useful to functionalize the residual biomass after extraction of extracellular polysaccharides and other highvalue products.

This study provided insights into the large potential of extracellular polysaccharides of P. cruentum as thickeningagents in food products. Even though the applied extraction procedures resulted in substantial co-extraction of proteins and minerals, with a polysaccharide content below $50 \%$ for most fractions, substantial viscosities were observed for EPS suspensions. As predicted by the high intrinsic viscosity of these polysaccharides, comparable or even higher than those of commercially used hydrocolloids, purified EPS might be a sustainable source of new thickening or gelling agents for food applications. For further 


\section{ACCEPTED MANUSCRIPT}

research, purification of the cell wall fractions is an interesting area, with the goal of obtaining pure polysaccharide fractions towards exploration of microalgae cell wall polysaccharide functionality. Although membrane filtration techniques have been proposed to obtain purified microalgal polysaccharides, alternative methods might be necessary to overcome the challenges associated with membrane filtration including fouling phenomena and losses of polysaccharides in the permeate.

\section{Acknowledgements}

T. Bernaerts and L. Gheysen are PhD fellows funded by the Research Foundation Flanders (FWO).

C. Kyomugasho is a postdoctoral researcher funded by the Onderzoeksfonds $\mathrm{KU}$ Leuven post-doctoral fellowship (PDM). In addition, financial support was obtained from the Research Fund KU Leuven $(\mathrm{KP} / 14 / 004)$.

\section{References}

Arad, S., \& Levy-Ontman, O. (2010). Red microalgal cell-wall polysaccharides: biotechnological aspects. Current Opinion in Biotechnology, 21, 358-364. https://doi.org/10.1016/j.copbio.2010.02.008

Arad, S., Rapoport, L., Moshkovich, A., van Moppes, D., Karpasas, M., Golan, R., \& Golan, Y. (2006). Superior Biølubricant from a Species of Red Microalga. Langmuir, 22, 7313-7317. https://doi.org/10.1021/la060600x

Beckett, S. T. (2012). Physico-Chemical Aspects of Food Processing. Springer.

Bernaerts, T. M. M., Gheysen, L., Kyomugasho, C., Jamsazzadeh Kermani, Z., Vandionant, S., Foubert, I., ... Van Loey, A. M. (2018). Comparison of microalgal biomasses as functional food ingredients: Focus on the composition of cell wall related polysaccharides. Algal Research, 32, 150-161. https://doi.org/10.1016/j.algal.2018.03.017

Blumenkrantz, N., \& Asboe-Hansen, G. (1973). New Method for Quantitative Determination of Uronic Acids. 


\section{ACCEPTED MANUSCRIPT}

Analytical Biochemistry, 54, 484-489. https://doi.org/10.1016/0003-2697(73)90377-1

Buono, S., Langellotti, A. L., Martello, A., Rinna, F., \& Fogliano, V. (2014). Functional ingredients from microalgae. Food \& Function, 5, 1669-1685. https://doi.org/10.1039/C4FO00125G

de Jesus Raposo, M. F., de Morais, A. M. M. B., \& de Morais, R. M. S. C. (2015). Bioactivity and Applications of Polysaccharides from Marine Microalgae. In Polysaccharides (pp. 1683-1727). Springer. https://doi.org/10.1007/978-3-319-16298-0

Dodgson, K. S., \& Price, R. G. (1962). A Note on the Determination of the Ester Sulphate Content of Sulphated Polysaccharides. Biochemical Journal, 84, 106-110.

Eteshola, E., Gottlieb, M., \& Arad, S. (1996). Dilute solution viscosity of red microalga exopolysaccharide. Chemical Engineering Science, 51(9), 1487-1494. https://doi.org/10.1016/0009-2509(95)00305-3

Eteshola, E., Karpasas, M., Arad, S., \& Gottlieb, M. (1998).Red microalga exopolysaccharides: 2. Study of the rheology, morphology and thermal gelation of aqueous preparations. Acta Polymerica, 49, 549-556. https://doi.org/10.1002/(SICI)1521-4044(199810)49:10/11<549::AID-APOL549>3.0.CO;2-T

Geresh, S., Adin, I., Yarmolinsky, E., \& Karpasas, M. (2002). Characterization of the extracellular polysaccharide of Porphyridium sp.: molecular weight determination and rheological properties. Carbohydrate Polymers, 50(2), 183-189. https://doi.org/10.1016/S0144-8617(02)00019-X

Geresh, S., \& Arad, S. (1991). The Extracellular Polysaccharides of the Red Microalgae: Chemistry and Rheology. Bioresource Technology, 38, 195-201. https://doi.org/10.1016/0960-8524(91)90154-C

Geresh, S., Arad, S. (Malis), Levy-Ontman, O., Zhang, W., Tekoah, Y., \& Glaser, R. (2009). Isolation and characterization of poly- and oligosaccharides from the red microalga Porphyridium sp. Carbohydrate Research, 344, 343-349. https://doi.org/10.1016/j.carres.2008.11.012

Geresh, S., Lupescu, N., \& Arad, S. (Malis). (1992). Fractionation and partial characterization of the sulphated polysaccharide of Porphyridium. Phytochemistry, 31(12), 4181-4186. https://doi.org/10.1016/00319422(92)80439-L 


\section{ACCEPTED MANUSCRIPT}

579

580

581

582

583

584

585

586

587

588

589

590

591

592

Gloaguen, V., Ruiz, G., Morvan, H., Mouradi-Givernaud, A., Maes, E., Krausz, P., \& Strecker, G. (2004). The extracellular polysaccharide of Porphyridium sp.: an NMR study of lithium-resistant oligosaccharidic fragments. Carbohydrate Research, 339, 97-103. https://doi.org/10.1016/j.carres.2003.09.020

Harding, S. E. (2005). Analysis of polysaccharides by ultracentrifugation. Size, conformation and interactions in solution. Advances in Polymer Science, 186, 211-254. https://doi.org/10.1007/b136821

Heaney-Kieras, J., \& Chapman, D. J. (1976). Structural studies on the extracellular polysaccharide of the red alga Porphyridium cruentum. Carbohydrate Research, 52, 169-177. https://doi.org/10.1016/S0008$6215(00) 85957-1$

Imeson, A. (1997). Thickening and Gelling Agents for Food (2nd ed.). Springer.

Imeson, A. (2011). Food Stabilisers, Thickeners and Gelling Agents. John Wiley \& Sons.

Jamsazzadeh Kermani, Z., Shpigelman, A., Bernaerts, T.M. M., Van Loey, A. M., \& Hendrickx, M. E. (2015). The effect of exogenous enzymes and mechanical treatment on mango purée: Effect on the molecular properties of pectic substances. Food Hydrocolloids, 50, 193-202. https://doi.org/10.1016/j.foodhyd.2015.03.033

Kavanagh, G. M., \& Ross-Murphy, S. B. (1998). Rheological Characterisation of Polymer Gels. Progress in Polymer Science, 23, 533-562.

Kyomugasho, C., Willemsen, K. L. D. D., Christiaens, S., Van Loey, A. M., \& Hendrickx, M. E. (2015). Pectin-interactions and in vitro bioaccessibility of calcium and iron in particulated tomato-based suspensions. Food Hydrocolloids, 49, 164-175. https://doi.org/10.1016/j.foodhyd.2015.03.011

Larson, R. G. (1999). The Structure and Rheology of Complex Fluids. New York: Oxford University Press.

Liberman, G. N., Ochbaum, G., Arad, S. (Malis), \& Bitton, R. (2016). The sulfated polysaccharide from a marine red microalga as a platform for the incorporation of zinc ions. Carbohydrate Polymers, 152, 658664. https://doi.org/10.1016/j.carbpol.2016.07.025

Lizarraga, M. S., De Piante Vicin, D., González, R., Rubiolo, A., \& Santiago, L. G. (2006). Rheological 


\section{ACCEPTED MANUSCRIPT}

603

604

605

606

607

608

609

610

behaviour of whey protein concentrate and lambda-carrageenan aqueous mixtures. Food Hydrocolloids, 20, 740-748. https://doi.org/10.1016/j.foodhyd.2005.07.007

Marcati, A., Ursu, A. V., Laroche, C., Soanen, N., Marchal, L., Jubeau, S., ... Michaud, P. (2014). Extraction and fractionation of polysaccharides and B-phycoerythrin from the microalga Porphyridium cruentum by membrane technology. Algal Research, 5, 258-263. https://doi.org/10.1016/j.algal.2014.03.006

Matos, J., Cardoso, C., Bandarra, N. M., \& Afonso, C. (2017). Microalgae as healthy ingredients for functional food: a review. Food \& Function, 8, 2672-2685. https://doi.org/10.1039/c7fo00409e

Patel, A. K., Laroche, C., Marcati, A., Ursu, A. V., Jubeau, S., Marchal, L., ... Michaud, P. (2013). Separation and fractionation of exopolysaccharide from Porphyridium cruentum. Bioresource Technology, 145, 345-350. https://doi.org/10.1016/j.biortech.2012.12.038

Rao, M. A. (2010). Rheology of Fluid and Semisolid Foods: Principles and Applications (2nd ed.). Springer.

Roussel, M., Villay, A., Delbac, F., Michaud, P., Laroche, C., Roriz, D., ... Diogon, M. (2015).

Antimicrosporidian activity of sulphated polysaccharides from algae and their potential to control honeybee nosemosis. Carbohydrate Polymers, 133, 213-220.

https://doi.org/10.1016/j.carbpol.2015.07.022

Saha, D., \& Bhattacharya, S. (2010). Hydrocolloids as thickening and gelling agents in food: a critical review. Journal of Food Science and Technology, 47(6), 587-597. https://doi.org/10.1007/s13197-010-0162-6

Shpigelman, A., Kyomugasho, C., Christiaens, S., Van Loey, A. M., \& Hendrickx, M. E. (2015). The effect of high pressure homogenization on pectin: Importance of pectin source and pH. Food Hydrocolloids, 43, 189-198. https://doi.org/10.1016/j.foodhyd.2014.05.019

Sila, D. N., Doungla, E., Smout, C., Van Loey, A., \& Hendrickx, M. (2006). Pectin Fraction Interconversions: Insight into Understanding Texture Evolution of Thermally Processed Carrots. Journal of Agricultural and Food Chemistry, 54(22), 8471-8479.

Singh, S., Arad, S., \& Richmond, A. (2000). Extracellular polysaccharide production in outdoor mass cultures 


\section{ACCEPTED MANUSCRIPT}

of Porphyridium sp. in flat plate glass reactors. Journal of Applied Phycology, 12, 269-275. https://doi.org/10.1023/A:1008177002226

629 Soanen, N., Da Silva, E., Gardarin, C., Michaud, P., \& Laroche, C. (2016). Improvement of 630 exopolysaccharide production by Porphyridium marinum. Bioresource Technology, 213, 231-238. https://doi.org/10.1016/j.biortech.2016.02.075

Whistler, R. (2012). Industrial Gums: Polysaccharides and Their Derivatives (2nd ed.). Academic Press, Inc.

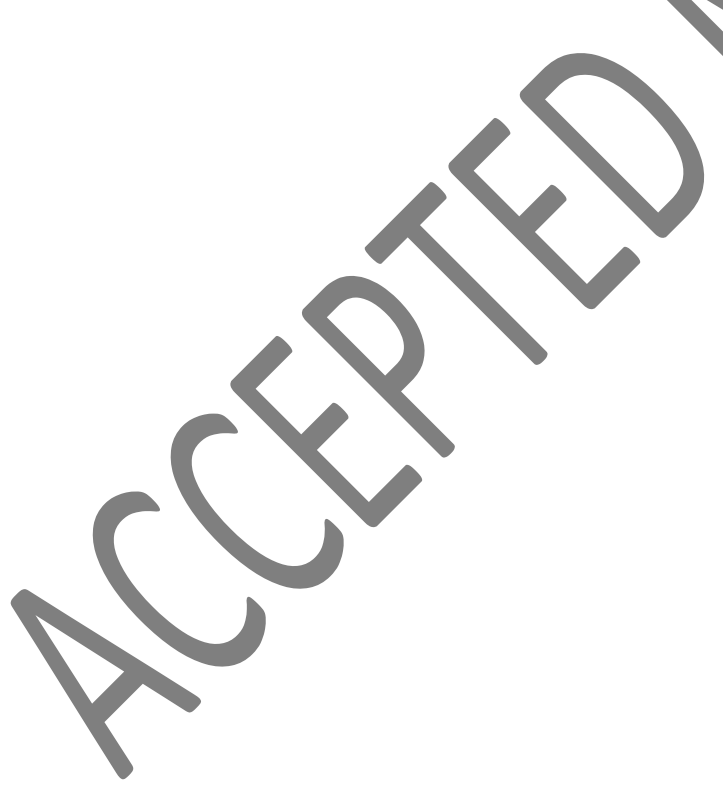

